\section{The cost of saving life}

The case conference on page 187 raises two particular ethical problems which must be faced by many doctors today. The first, imposed by diminishing financial resources of the National Health Service at a time of rapid development of new, effective, but costly methods of treatment, concerns decisions as to which patients with what diseases shall be optimally treated and which shall not. Such choices may be matters of life and death. (It is relevant to note that, had the patient not died, this case would probably not have been offered for discussion, even though the ethical issues would have been the same.) The choices are often solved by evasion of the issue as when more expensive rather than cheaper drugs are routinely prescribed, depleting resources which might otherwise have been used to buy life-saving machinery or materials for other patients, or, as in the case in question, when the excessive expense of treatment of a particular patient is only considered after the event. Two of our commentators effectively advocate such evasion: one argues that there must always be 'the fullest use of effective resources' - without considering the ethics of priorities in their use. The other points out that the law demands 'proper facilities for the best possible treatment of all cases in hospital'. If this is true, the law is still (to use $\mathrm{Mr}$ Bumble's phrase) an ass and needs revision, for practitioners can no longer 'expect the hospital authorities to provide all the proper facilities' for treatment. At present, few doctors are accustomed to considering financial reasons for a choice of treatment.

The second question is how to weigh, in deciding priorities, the quality and value of the life which patients are likely to have after their treatment. It is of course, theoretically true that moral problems 'can only be clearly faced with sufficient knowledge of all relevant patients'. Since such knowledge is only available in specific choices (as between two or more patients requiring haemodialysis when only one place is available in the unit), these questions have to be answered without such knowledge. In the particular case we are considering, the only doubt about the quality of his future life was raised by his age and nothing was known about the alternative patients who might have benefited if $£ 8500$ had not been spent on his treatment. This absence of any clear frame of reference for deciding on treatment is normal and is no excuse for reflexly adopting the principle that every available resource should be used for every patient. This patient's age does not appear to have impaired his quality of life, which, it was hoped, could easily be restored when treatment was started. But, as unforseen complications arose, the chances of unimpaired recovery receded and at the same time, the cost of treatment, both financial and in terms of the patient's discomfort and pain, increased sharply. Consideration of the patient's quality of life, and more urgently, quality of his death became important. Death from haemorrhage is peaceful and painless: postoperative death from peritonitis can be painful and distressing. Experienced clinical judgment is needed to assess the relative distress that will be caused by one or another line of action. Does the training in ethics that most doctors receive today enable them even to consider allowing a patient to bleed to death rather than to stand the rigours of an operation which will be painful and has only a slender chance of prolonging his life?

\section{Sterilization}

The recent case of an I I-year-old girl from Sheffield who was protected by a court order from a proposed sterilization operation on social grounds raises a number of important issues. The first concerns the attention paid to the case by the news media. We are printing in this number an edited version of the BBC television discussion of the case. This programme was screened at a time of widespread public interest in the issue, stimulated by regular and detailed press reports of the opposing arguments. Such publicity seems to us entirely healthy and commendable. Journalists are frequently accused of sensationalism in the presentation of medical topics but when human rights are involved and they are rarely absent in the practice of medicine - it is essential that medical decisions are exposed to public scrutiny. Compared with the moral hazards of concealment, the risks of distortion of the facts by the media are more than acceptable.

A second point concerns the responsibilities of central health authorities in monitoring medical procedures. It became evident from questions in the 